\title{
Respiratory mechanics in patients ventilated for critical lung disease
}

\author{
L. Beydon*, C. Svantesson**, K. Brauer*, F. Lemaire*, B. Jonson**
}

Respiratory mechanics in patients ventilated for critical lung disease. L. Beydon, C. Svantesson, K. Brauer, F. Lemaire, B. Jonson. @ ERS Journals Ltd 1996.

ABSTRACT: Respiratory mechanics, using flow interruption, was previously studied during the complete breath in healthy ventilated man, with numerical techniques relieving constraints regarding flow pattern. The classical linear model of nonNewtonian behaviour was found to be valid. The present study was extended to subjects with critical lung disease.

Subjects with acute lung injury (ALI; $n=2)$, acute respiratory distress syndrome (ARDS; $n=4$ ), and chronic obstructive pulmonary disease (COPD; $n=3$ ) were studied with and without positive end-expiratory pressure (PEEP). Functional residual capacity $(\mathrm{FRC})$ was measured with sulphur hexafluoride $\left(\mathrm{SF}_{6}\right)$ wash-out.

The static pressure-volume (P-V) curve was linear at zero end-expiratory pressure (ZEEP), but nonlinear at PEEP. Its hysteresis was nonsignificant. In ALI/ ARDS, PEEP increased lung volume by distension and recruitment, but only by distension in COPD. In ALI/ARDS, resistance was increased, at ZEEP. In COPD, resistance became extremely high during expiration at ZEEP. In ALI/ARDS at ZEEP, non-Newtonian behaviour, representing tissue stress relaxation and pendelluft, complied with the classical linear model. At PEEP, the non-Newtonian compliance became volume-dependent to an extent correlated to the nonlinearity of the static P-V curve. In COPD, non-Newtonian behaviour was adequately explained only with a model with different inspiratory and expiratory behaviour.

The classical model of the respiratory system is valid in ALI/ARDS at ZEEP. More advanced models are needed at PEEP and in COPD. Eur Respir J., 1996, 9, 262-273.
The flow interruption method has been used for studies both in ventilated humans and animals. The analysis has been based on a classical model. This model includes a Newtonian resistor $(R)$ representing mainly airway resistance [1], a Newtonian capacitor $(C)$ representing the static pressure-volume $(P-V)$ relationship and a unit, that comprises a resistor $(R \mathrm{ve})$ and a capacitor $(C \mathrm{ve})$ (fig. 1), which reflects non-Newtonian behaviour due to ventilation inhomogeneity (pendelluft) and tissue viscoelasticity (stress adaptation). It is well-known that these two phenomena cannot be distinguished on the basis of pressure and flow measured at the airway opening $[1,2]$. It will be discussed below that $R$ ve and $C_{\text {ve }}$ probably represent tissue viscoelasticity to a greater extent than pendelluft in the present context. $R$ ve and $C_{\mathrm{ve}}$ will together be denoted the viscoelastic unit, to be considered in a broad sense. Due to methodological limitations, most studies have been limited to inspiration and constant flow [2-16]. Recently, we modified the flow interruption technique to improve accuracy of data acquisition and analysis [17]. $R_{\text {ve }}$ and $C_{\text {ve }}$ were estimated with a numerical iterative method. This method is not limited to a particular flow pattern. This enabled an analysis of the complete respiratory cycle. In normal subjects, the static $P-V$ curve was linear. The static $P-V$
* Medical and Surgical Intensive Care Units, INSERM U296, Hôpital H. Mondor, Créteil, France. **Dept of Clinical Physiology, University Hospital of Lund, Lund, Sweden.

Correspondence: B. Jonson Dept of Clinical Physiology University Hospital of Lund S-221 85 Lund

Sweden

Keywords: Acute lung injury chronic obstructive pulmonary disease human lung nonlinear mechanics viscoelasticity

Received: January 51995

Accepted after revision October 41995

This study was supported by the Swedish Medical Research Council (grant 2872), the Swedish Heart Lung Foundation and INSERM U296, France. curve did not show any hysteresis over the tidal volume. $R$ was independent of flow and volume during inspiration but increased during expiration. Non-Newtonian behaviour, thought to represent tissue viscoelasticity, fully accorded with the model in which $R$ ve and $C$ ve are constant during a breath.

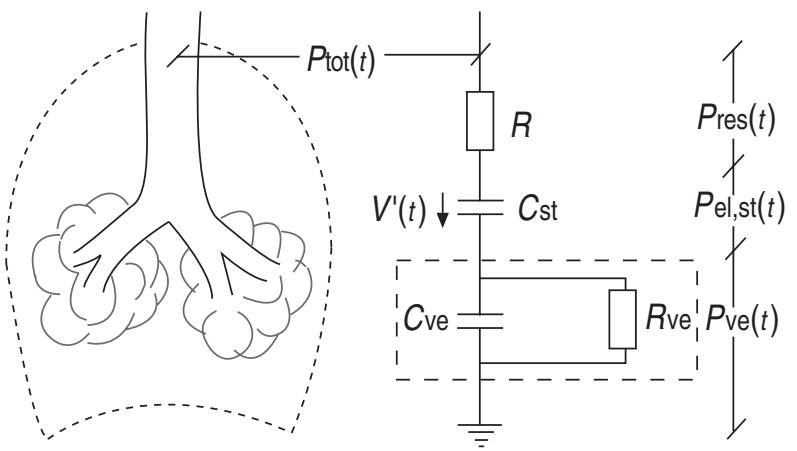

Fig. 1. - The model of the respiratory system. A "Newtonian unit" incorporates a resistor $(R)$, which mainly represents airway resistance, and a capacitor $(C \mathrm{st})$, which defines static compliance. A "viscoelastic unit" comprises a capacitor $\left(C_{\mathrm{ve}}\right)$ and a resistor $\left(R_{\mathrm{ve}}\right)$. At a certain moment $(t)$ the pressure gradients within the system are denoted

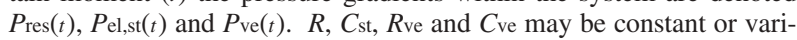
able. $P$ res: resistive pressure; $P$ el,st: static elastic recoil pressure; $P_{\text {ve: }}$ pressure over the viscoelastic unit. 
The aim of the present study was a comprehensive analysis of the mechanical behaviour of the respiratory system, over the complete respiratory cycle, in a spectrum of subjects with critical lung disease. Nonlinear behaviour of the Newtonian components in subjects with lung disease is known [8-10, 14-16, 18]. However, the validity of a linear model of the viscoelastic unit has not been systematically analysed. Therefore, the validity of the classical model with constant $R$ ve and $C$ ve, was tested.

More composite, nonlinear models were tried when the classical model failed. Numerical techniques that are well-suited for analysis of nonlinear systems [19] were applied.

\section{Material and methods}

\section{Subjects and ventilation}

The study was approved by the local Ethics Committee. Nine intubated subjects (table 1), ventilated for critical lung disease, were studied in the supine position. Two of them met the criteria for acute lung injury (ALI) and four for acute respiratory distress syndrome (ARDS) according to American-European consensus [20]. Three subjects had been treated for chronic obstructive pulmonary disease (COPD) for years. They were ventilated during an acute exacerbation.

The study was performed after traditional initial stabilization for 1 day or more in all subjects. Treatment included dehydration, administration of cardiotropic drugs and bronchodilatation, according to clinical needs. Pulmonary capillary wedge pressure was below $1.5 \mathrm{kPa}$ and cardiac output was normal. The patients had no pleural effusion or pneumothorax at the time of the study. Clinical and haemodynamic conditions were stable. The subjects were sedated with fentanyl $\left(5 \mu \mathrm{g} \cdot \mathrm{kg}^{-1}\right)$ and midazolam $\left(0.15 \mathrm{mg} \cdot \mathrm{kg}^{-1}\right)$. Paralysis was maintained during the study with pancuronium bromide, $0.15 \mathrm{mg} \cdot \mathrm{kg}^{-1}$. Routine care, such as tracheal aspiration, was performed some minutes before the study. Volume-controlled ventilation was delivered with a Servo Ventilator 900C (Siemens-Elema AB, Solna, Sweden), using a constant inspiratory flow pattern. The inspiratory time was $25 \%$ and the postinspiratory pause $10 \%$ of the respiratory cycle. Respiratory frequency, tidal volume, and fractional inspiratory oxygen $\left(\mathrm{F}, \mathrm{O}_{2}\right)$ were individually set as required. In ALI/ARDS a positive end-expiratory pressure (PEEP) was set according to "the best PEEP" level. The level was determined from the "inflection" point of the $P / V$ curve at which compliance is observed to increase rapidly during the super syringe test, that was used as a part of the clinical routine [21, 22]. In subject No. 8, PEEP was needed to avoid hypoxia. Lung mechanics were studied at that level of PEEP and at zero end-expiratory pressure (ZEEP). Subject No. 5 became hypoxic at ZEEP and, therefore, PEEP was only reduced from 1.3 to $0.6 \mathrm{kPa}$. In subjects Nos. 7 and 9, who did not require PEEP, an arbitrary level of PEEP was temporarily set during the study.

\section{Modelling of the respiratory system}

The respiratory system was modelled for Newtonian resistance and compliance and for non-Newtonian behaviour (fig. 1). The Newtonian resistor $(R)$ represents mainly airway resistance [1]. The static elastic properties of lung and chest wall are represented by a capacitor

Table 1. - Subject characteristics and diagnosis

\begin{tabular}{|c|c|c|c|c|c|c|c|c|}
\hline $\begin{array}{l}\text { Sub. } \\
\text { No. }\end{array}$ & Sex & $\begin{array}{l}\text { Height } \\
\mathrm{cm}\end{array}$ & $\begin{array}{l}\text { Weight } \\
\mathrm{kg}\end{array}$ & $\begin{array}{l}\text { Age } \\
\text { yrs }\end{array}$ & Diagnosis & $\begin{array}{l}V \mathrm{~T} \\
\mathrm{~mL} \cdot \mathrm{kg}^{-1}\end{array}$ & $\begin{array}{l}\text { PEEP* } \\
\mathrm{kPa}\end{array}$ & $\begin{array}{l}P_{\mathrm{a}, \mathrm{O}_{2}} / F_{\mathrm{I}}, \mathrm{O}_{2} \\
\mathrm{mmHg}\end{array}$ \\
\hline 1 & M & 156 & 63 & 81 & $\begin{array}{l}\text { ALI, } \\
\text { pneumonia }\end{array}$ & 10.7 & 1.0 & 260 \\
\hline 2 & M & 165 & 78 & 70 & $\begin{array}{l}\text { ARDS, } \\
\text { coronary insufficiency }\end{array}$ & 10.2 & 1.2 & 110 \\
\hline 3 & M & 176 & 75 & 22 & $\begin{array}{l}\text { ALI, } \\
\text { chest trauma }\end{array}$ & 11.7 & 1.0 & 217 \\
\hline 4 & M & 170 & 54 & 45 & $\begin{array}{l}\text { ARDS, } \\
\text { pneumonia }\end{array}$ & 10.7 & 1.0 & 88 \\
\hline 5 & M & 167 & 69 & 60 & $\begin{array}{l}\text { ARDS, } \\
\text { coronary insufficiency, } \\
\text { sepsis }\end{array}$ & 9.5 & 1.3 & 78 \\
\hline 6 & M & 164 & 50 & 38 & $\begin{array}{l}\text { ARDS, } \\
\text { Pneumocystis }\end{array}$ & 18.3 & 0.8 & 88 \\
\hline 7 & M & 169 & 88 & 74 & $\begin{array}{l}\text { COPD, } \\
\text { lymphangitis } \\
\text { carcinomatosa }\end{array}$ & 10.2 & 0 & 289 \\
\hline 8 & $\mathrm{~F}$ & 145 & 33 & 51 & $\begin{array}{l}\text { COPD } \\
\text { exacerbation }\end{array}$ & 13.6 & 0.8 & 168 \\
\hline 9 & M & 162 & 70 & 75 & $\begin{array}{l}\text { COPD } \\
\text { exacerbation }\end{array}$ & 9.1 & 0 & 44 \\
\hline
\end{tabular}

*: the value represents PEEP applied clinically based upon the "best PEEP level" [12]. Sub: subject; M: male; F: female; ALI: acute lung injury; ARDS: acute respiratory distress syndrome; COPD: chronic obstructive pulmonary disease; $V \mathrm{~T}$ : tidal volume; PEEP: positive end-expiratory pressure; $\mathrm{Pa}_{\mathrm{a}, \mathrm{O}_{2}} / \mathrm{FI}_{\mathrm{I}} \mathrm{O}_{2}$ : arterial oxygen tension over fraction of inspired oxygen. 
$\left(C_{\mathrm{st}}\right)$. The non-Newtonian properties of the respiratory system are represented by a capacitor $(C$ ve $)$ and a resistor $(R v e)$ mounted in parallel. The product $R v$ ve $C$ ve defines the time constant of the viscoelastic unit $\left(\tau_{\mathrm{ve}}\right)$. The pressure over the viscoelastic unit will be denoted $P_{\mathrm{ve}}$. For a linear viscoelastic unit, which implies that $R$ ve and $C_{\mathrm{ve}}$ are constant, the rate of change of $P_{\mathrm{ve}}$ with time can be expressed as:

$$
\mathrm{d} P \operatorname{ve}(t) / \mathrm{d} t=V^{\prime}(t) / C_{\mathrm{ve}}-P_{\mathrm{ve}}(t) /\left[R_{\mathrm{ve}} \cdot C_{\mathrm{ve}}\right]
$$

Equation (1) is well known [2] and was recently explored using a numerical iterative technique [17]. The equation can be extended to nonlinear models with variable values of $C_{\text {ve }}$ and $R$ ve. For instance in this study, we have allowed $C$ ve to vary with volume charge of the capacitor, which is a function of time $\left(V_{\mathrm{ve}}(t)\right)$ :

$\mathrm{d} P \operatorname{ve}(t) / \mathrm{d} t=V^{\prime}(t) / C \mathrm{ve}\left(V_{\mathrm{ve}}(t)\right)-P \mathrm{ve}(t) /\left[R \mathrm{ve} \cdot C \operatorname{ve}\left(V_{\mathrm{ve}}(t)\right)\right]$

Equations (1) and (2) are valid at any moment and apply to any flow pattern. Equation (2) cannot be rearranged to give an explicit expression for $V^{\prime}(t)$. Hence, parameter estimations based on these equations require numerical iterative techniques [17]. Variation of $C_{\text {ve with respect }}$ to its volume charge was accomplished by letting $P_{\mathrm{ve}}$ vary nonlinearly with $V_{\mathrm{ve}}(t)$ :

$$
P \mathrm{ve}(t)=\mathrm{k} 1, \mathrm{ve} \cdot V_{\mathrm{ve}}(t)+\mathrm{k} 2, \mathrm{ve} \cdot V_{\mathrm{ve}}(t)^{2}
$$

Equation (3) is differentiated with respect to volume:

$$
\mathrm{d} P \mathrm{ve}(t) / \mathrm{d} V \mathrm{ve}(t)=\mathrm{k} 1, \mathrm{ve}+2 \cdot \mathrm{k} 2, \mathrm{ve} \cdot V_{\mathrm{ve}}(t)
$$

By definition $\mathrm{d} P \mathrm{ve}(t) / \mathrm{d} V_{\mathrm{ve}}(t)$ is the viscoelastic elastance at volume $V_{\mathrm{ve}}(t)$. Accordingly, $C \mathrm{ve}\left(V_{\mathrm{ve}}(t)\right)$ becomes:

$$
C_{\mathrm{ve}}\left(V_{\mathrm{ve}}(t)\right)=1 /\left[\mathrm{k} 1, \mathrm{ve}+2 \cdot \mathrm{k} 2, \mathrm{ve} \cdot V_{\mathrm{ve}}(t)\right]
$$

\section{The flow interruption technique}

The classical flow interruption method was modified as described in detail in a previous paper [17]. Only key features of the method will be reported here. The ventilator system was carefully checked for leaks. A number of "study breaths", each preceded by some identical undisturbed breaths, were interrupted at various moments of the respiratory cycle (fig. 2). Each study breath gives information about $R$, static elastic pressure $(P \mathrm{el}, \mathrm{st})$, and $P_{\text {ve. }}$ After the interruption, no further information is retrieved from the breath. The volume reference point for expiratory study breaths was obtained at onset of inspiration before the interrupted expiration. A device for external control of the ventilator [17] overrides the frequency set on the ventilator, but only during the inspiratory phase for an inspiratory study breath and vice versa for an expiratory study breath. It allowed interruption of a study breath without any influence on ventilation before the moment of interruption. Ventilator tubings

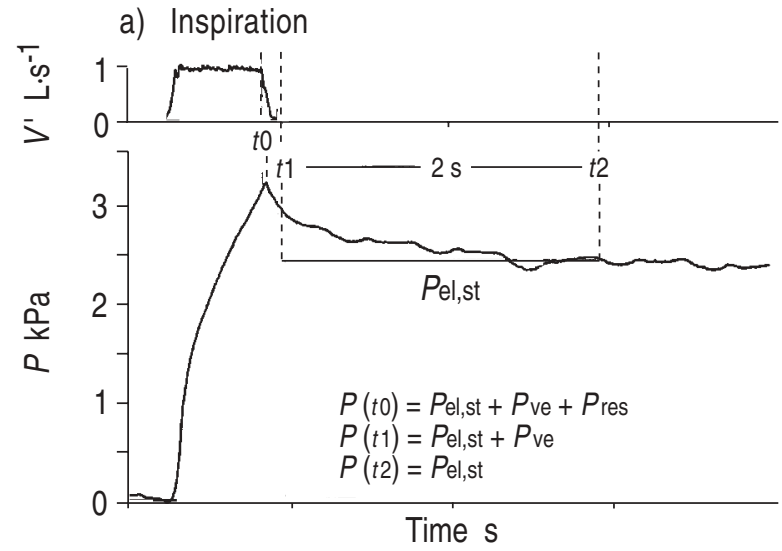

b) Expiration

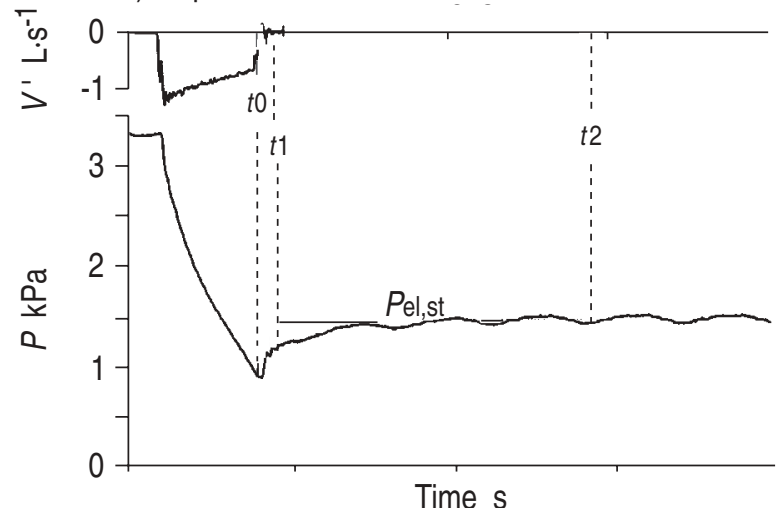

Fig. 2. - a) Inspiratory study breath from subject No. 3. b) Expiratory study breath from subject No. 3. Tracheal pressure $(P)$ comprises: at $t 0$ just before flow $\left(V^{\prime}\right)$ interruption $P$ el,st, $P_{\mathrm{ve}}$, and $P$ res; at $t 1$ immediately after flow interruption $P$ el,st and $P_{\mathrm{ve}}$; and at $t 22 \mathrm{~s}$ later only $P$ el,st. Note that pressure increased during the pause after the interrupted expiration that indicates increased stress. For further abbreviations see legend to figure 1 .

of minimal resistance and compliance were used. Each value of flow rate sampled was corrected with respect to gas compression in the connecting tubes.

Intratracheal pressure was measured with a Validyne transducer (MP45) and a catheter ending about $4 \mathrm{~cm}$ beyond the tip of the tracheal tube, where effects of changing diameter of the conduit have died away. Flow was measured with the transducers of the ventilator. The 10-90\% response time to a square-wave pressure or flow change was $5 \mathrm{~ms}$. The time lag differed between signals less than $3 \mathrm{~ms}$. Both pressure and flow measuring systems were optimally dampened. Anti-aliasing filters with a cut-off frequency of $100 \mathrm{~Hz}$ were applied before the signals were recorded with a computer after analogue-to-digital (A/D)-conversion at $200 \mathrm{~Hz}$. During expiration, lung volume returns to the same volume as before inspiration. In spite of this, measured expiratory volumes may differ from measured inspiratory volumes because of technical limitations, gas humidification, and effects of the respiratory quotient. The calibration of expiratory flow was, therefore, adjusted so that expired volume was identical to inspired volume for ordinary breaths. After interruption of the study breath, pressure was analysed during a pause of $3 \mathrm{~s}$. Heart artefacts were corrected for by fitting a polynomial equation to the pressure signal recorded during 3-4 heart cycles occurring 
during the pause following interruption as described previously [17]. The pressure immediately before interruption (measured at $t 0)$ was denoted total pressure $(P$ tot). It comprised resistive pressure $(P$ res $)$, static elastic recoil pressure $(P \mathrm{el}, \mathrm{st})$, and the pressure over the viscoelastic unit $\left(P_{\mathrm{ve}}\right)$. P tot was corrected for the volume change taking place during the finite closing time of the expiratory valve of the Servo Ventilator, as described previously [23]. The volume change during closure was measured for each study breath. The change of pressure that would occur during the same volume interval if the breath had not been interrupted was added to $P$ tot $(t 0)$ and, thereby, to Pres (fig. 2) before calculation of resistance, as described previously [17].

The dynamic elastic recoil pressure $(P$ el,dyn $)$, which is the sum of $P$ el,st and $P_{\mathrm{ve}}$, was read immediately after flow cessation (at instant $t 1$ ). Pres was calculated as the difference between $P$ tot and $P$ el,dyn. $P$ el,st was measured $2 \mathrm{~s}$ after flow cessation (at instant $t 2$ ). The amount of gas trapped in the lung above the elastic equilibrium point, Vtrap, was assessed by clamping the inspiratory valve for a few cycles, during which expired volumes were recorded and summed [24]. The start of a study breath and $t 1$ were, under computer/observer interaction, defined from moments of flow transition, whilst $t 0$ was defined as the moment preceding flow deceleration. All values were then read by the computer program. Observations were limited to the tidal volume range.

Resistance $(R)$ was calculated as $P$ res $/ V^{\prime}(t 0)$. The volume relative to functional residual capacity (FRC) $(V)$ at the moment of flow interruption, was calculated by integration of flow from the start of inspiration. Work dissipated within the respiratory system during a breath was calculated from the area of the $P_{\text {tot }} / V$ loop. FRC was determined with the wash-in/wash-out technique of sulphur hexafluoride $\left(\mathrm{SF}_{6}\right)$ [25]. To reach a stable alveolar concentration of $\mathrm{SF}_{6} 10 \mathrm{~min}$ of equilibration were allowed in ALI/ARDS patients and $20 \mathrm{~min}$ in COPD patients.

\section{Analysis of non-Newtonian behaviour}

Calculation of $\tau_{\mathrm{ve}}, C_{\mathrm{ve}}, R_{\mathrm{ve}}$, and non-Newtonian work was performed as follows. Firstly, we analysed data from all subjects using the linear model, i.e. a model with constant non-Newtonian parameters. $\tau_{\mathrm{ve}}$ was calculated from a polynomial describing the pressure curve during the pause. This was the polynomial used for heart artefact correction. $P$ el,st was subtracted from this curve to obtain an estimate of $P \mathrm{ve}(t)$, that was fitted to the following equation to estimate $\tau_{\mathrm{ve}}$.

$$
P_{\mathrm{ve}}(t)=P_{\mathrm{ve}}(t 1) \cdot \mathrm{e}^{-\mathrm{t} / \tau \mathrm{ve}}
$$

The value of $P$ el,st used in this procedure is slightly overestimated because of the fact that $P_{\mathrm{ve}}(t)$ has not reached zero after $2 \mathrm{~s}$. As $P$ ve is considered to fall to this inexact value of $P$ el,st, an error is introduced in the calculation of $\tau_{\mathrm{ve}}$. This error will cause a bias toward lower values. The error will depend on the interval of the polynomial that is used for calculation of $P$ ve $(t)$. Theoretical analysis shows that for intervals of up to $1 \mathrm{~s}$ the error will be $4-10 \%$. If up to $2 \mathrm{~s}$ had been used, the error would increase rapidly to about $33 \%$. We used the polynomial equation up to $1 \mathrm{~s}$ in order to minimize the error and yet use as much as possible of the original information.

Calculation of $C$ ve was performed with a previously described numerical iterative technique [17]. The value of $C_{\mathrm{ve}}$ was estimated according to the principle of the least sum of squares between observed values of $P_{\mathrm{ve}}$ and the calculated theoretical course of $P$ ve. Rve was finally calculated as $\tau_{\mathrm{ve}} / C_{\mathrm{ve}}$.

A nonlinear model, in which $C$ ve varied according to Equation (5), was also tested. Then $\tau_{\mathrm{ve}}$ is a variable that cannot be defined as above. Therefore, each of the coefficients, k1,ve, k2,ve and $R$ ve was estimated in an iterative process. For each moment represented by a recorded value of flow the value of $C \mathrm{ve}\left(V_{\mathrm{ve}}(t)\right)$ was calculated according to Equation 5. The change of $P_{\mathrm{ve}}(t)$ for the same moment was then calculated according to Equation (2). This process was repeated for each flow sample of the normal breath and the sum of squared differences was determined in the same way as for the linear model. One of the coefficients was then changed by a small amount and the process was repeated until the combination of values of $\mathrm{k} 1$, ve, $\mathrm{k} 2$, ve and $R \mathrm{ve}$ that gave minimal sum of squared differences was obtained. The whole process was repeated with various initial values of the coefficients to guarantee a homogenous convergence and, thereby, a unique solution. The significance of the improved fit between observed and calculated values of $P_{\text {ve }}$ obtained with the nonlinear model, was evaluated according to an F-ratio test. If an adequate fit was still not obtained, as was only the case in obstructive lung disease, we considered that non-Newtonian properties might differ between inspiration and expiration. Accordingly, we estimated separate parameters of the viscoelastic unit for inspiration and expiration. This model was denoted "the composite model".

The total work dissipated within the viscoelastic unit during a breath $\left(W_{\mathrm{ve}}\right)$ was calculated from the area of the $P$ ve/ $V$ loops (fig. 3).

\section{Results}

\section{Newtonian behaviour}

Heart beat induced variations in tracheal pressure were on average $0.055 \mathrm{kPa}$ and were of the same magnitude as $P$ res and $P$ ve.

To evaluate static hysteresis, the mid-tidal difference between the inspiratory and expiratory $P$ el,st was analysed. There was no significant difference either at ZEEP or at PEEP $(0.044 \pm 0.096 \mathrm{kPa}$ and $0.060 \pm 0.12 \mathrm{kPa}$, respectively). Figure 4 shows typical $P$ el,st $V$ curves. In each subject, data from all inspiratory and expiratory study breaths were pooled and fitted to a first or second degree polynomial:

$$
P \text { el,st }=\mathrm{k} 0, \mathrm{st}+\mathrm{k} 1, \mathrm{st} \cdot V+\mathrm{k} 2, \mathrm{st} \cdot V^{2}
$$

The linear equation provided an adequate fit to observed data in each of the eight subjects studied at ZEEP. 

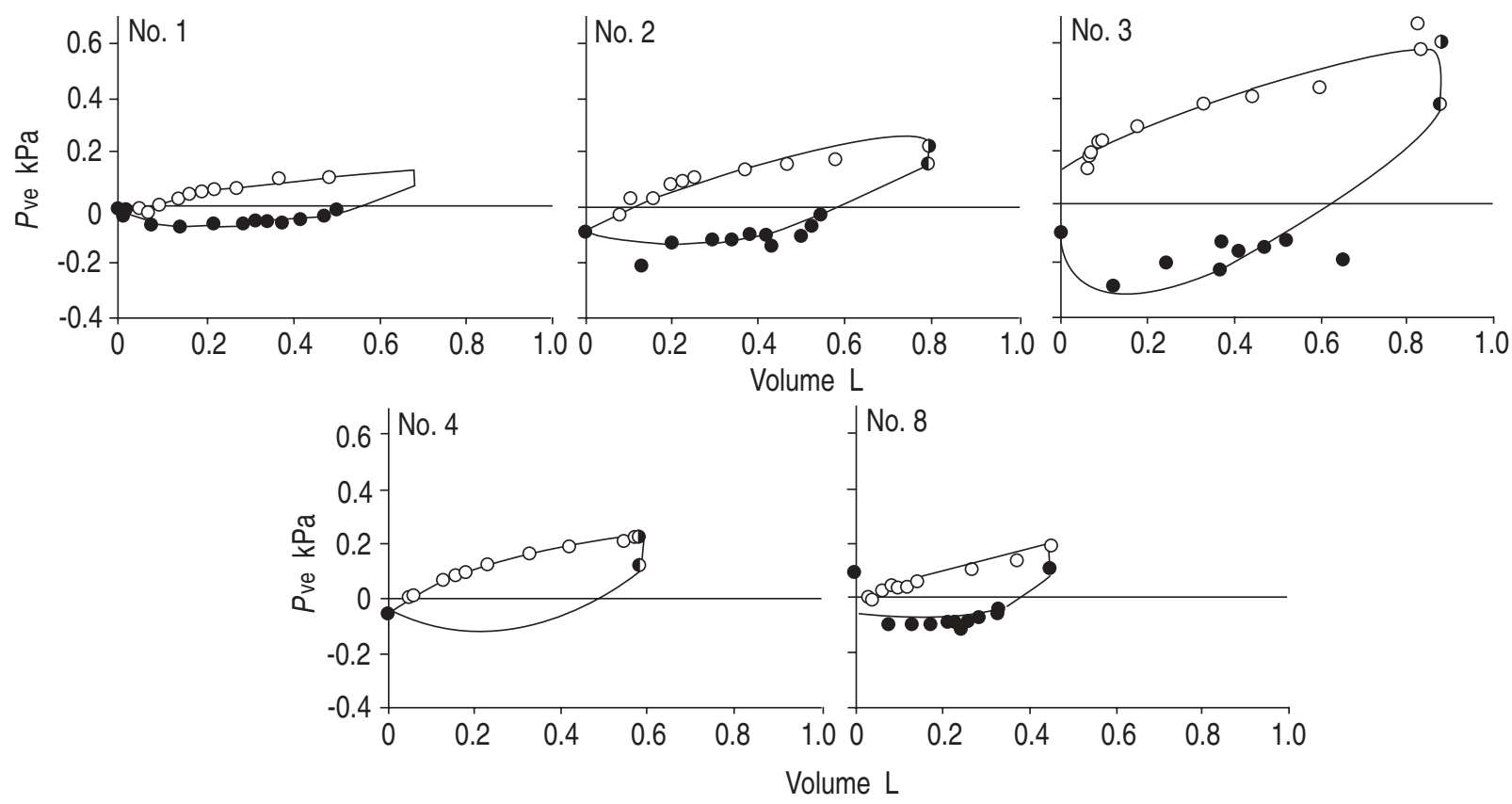

Fig. 3. - The calculated trajectory of $P_{\text {ve }}$ compared to data observed in five subjects (subjects Nos. 1-4 and 8) in whom the linear model was accepted at ZEEP. $\bigcirc$ : inspiration; $\bullet$ : postinspiratory pause; $\bullet$ : expiration. Expiratory data were lost in subject No. 4. ZEEP: zero end-expiratory pressure; $P$ ve: pressure over the viscoelastic unit.
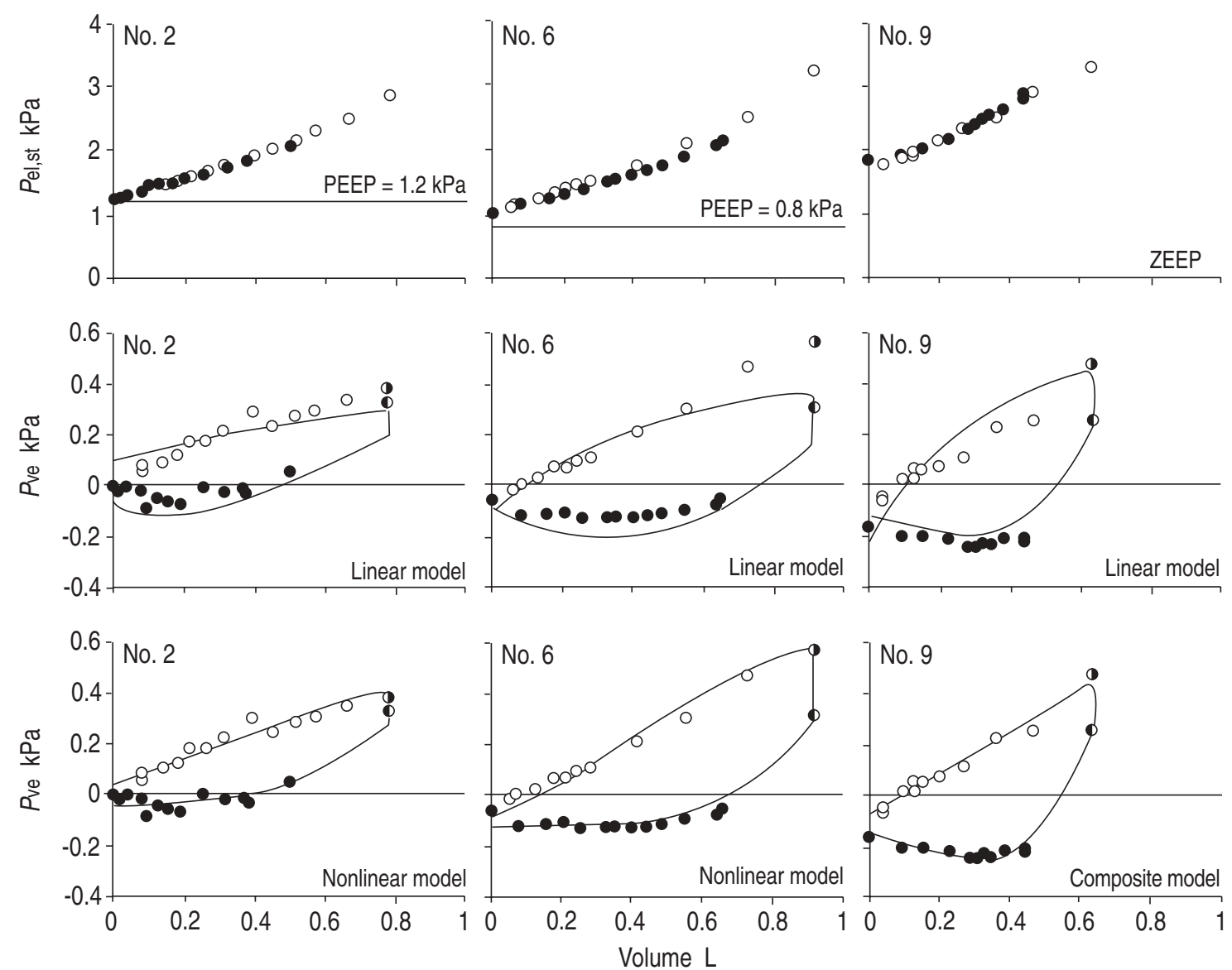

Fig. 4. - $P$ el,st and $P_{\mathrm{ve}}$ data during inspiration (O) and expiration (•) plotted against volume for subject No. 2 at PEEP $1.2 \mathrm{kPa}$, subject No. 6 at PEEP $0.8 \mathrm{kPa}$ and subject No. 9 at ZEEP. Upper panels: the $P$ el,st $/ V$ relationship showed no significant hysteresis. Middle panels: in each of the subjects the trajectory deviated systematically from the data points. Lower panels: in subjects Nos. 2 and 6 the nonlinear model improved the visual fit and reduced the sum of squared differences between calculated trajectory and data points observed to less than a third compared to the linear model. In subject No. 9 only the composite model improved the fit significantly. PEEP: positive end-expiratory pressure. For further abbreviations see legends to figures 1 and 3 . 
Table 2. - Volumes and static elastic properties

\begin{tabular}{|c|c|c|c|c|c|c|c|c|c|c|c|c|}
\hline \multirow[b]{2}{*}{$\begin{array}{l}\text { Sub } \\
\text { No. }\end{array}$} & \multirow[b]{2}{*}{$\begin{array}{l}\text { PEEP } \\
\mathrm{kPa}\end{array}$} & \multirow[b]{2}{*}{$\begin{array}{c}\text { Auto-PEEP } \\
\mathrm{kPa}\end{array}$} & \multirow[b]{2}{*}{$\begin{array}{c}V \mathrm{~T} \\
\mathrm{~L}\end{array}$} & \multirow[b]{2}{*}{$\begin{array}{c}\text { FRC } \\
\mathrm{L}\end{array}$} & \multirow[b]{2}{*}{$\begin{array}{c}V_{\text {trap }} \\
\mathrm{mL}\end{array}$} & \multicolumn{3}{|c|}{$P \mathrm{el}, \mathrm{st}$} & \multicolumn{2}{|c|}{$C_{\mathrm{st}}$} & \multirow{2}{*}{$\begin{array}{c}\text { Mid-tidal } \\
R \mathrm{I} \\
\mathrm{kPa} \cdot \mathrm{L}^{-1} \cdot \mathrm{s}\end{array}$} & \multirow{2}{*}{$\begin{array}{l}\text { Mid-tidal } \\
\quad R \mathrm{E} \\
\mathrm{kPa} \cdot \mathrm{L}^{-1} \cdot \mathrm{S}\end{array}$} \\
\hline & & & & & & $\begin{array}{l}\mathrm{k} 0 \text {,st } \\
\mathrm{kPa}\end{array}$ & $\begin{array}{c}\mathrm{k} 1 \text {,st } \\
\mathrm{kPa} \cdot \mathrm{L}^{-1}\end{array}$ & $\begin{array}{c}\mathrm{k} 2 \text {,st } \\
\mathrm{kPa} \cdot \mathrm{L}^{-2}\end{array}$ & $\begin{array}{l}\text { Preinsp. } \\
\mathrm{L} \cdot \mathrm{kPa}^{-1}\end{array}$ & $\begin{array}{l}\text { Postinsp. } \\
\mathrm{L} \cdot \mathrm{kPa}^{-1}\end{array}$ & & \\
\hline \multirow[t]{2}{*}{1} & - & 0.19 & 0.68 & 1.8 & 187 & 0.19 & 1.34 & - & 0.75 & $*$ & 0.43 & 0.33 \\
\hline & 1.0 & 0.10 & 0.68 & 3.2 & 8 & 1.12 & 1.48 & 0.55 & 0.68 & 0.45 & 0.27 & 0.23 \\
\hline \multirow[t]{2}{*}{2} & - & 0.20 & 0.79 & 1.5 & 136 & 0.30 & 1.84 & - & 0.54 & $*$ & 0.58 & 0.56 \\
\hline & 1.2 & 0.08 & 0.78 & 2.4 & 12 & 1.28 & 1.13 & 1.05 & 0.89 & 0.36 & 0.28 & 0.26 \\
\hline \multirow[t]{2}{*}{3} & - & 0.20 & 0.88 & 1.0 & 29 & 0.46 & 3.05 & - & 0.33 & $*$ & 0.48 & 0.59 \\
\hline & 1.0 & 0.20 & 0.92 & 1.4 & 28 & 1.30 & 2.24 & 0.61 & 0.45 & 0.30 & 0.47 & 0.37 \\
\hline \multirow[t]{2}{*}{4} & - & 0.14 & 0.59 & - & 93 & 0.14 & 2.35 & - & 0.43 & $*$ & 0.49 & - \\
\hline & 1.0 & 0.17 & 0.71 & - & 20 & 1.17 & 1.34 & 1.78 & 0.74 & 0.26 & 0.41 & 0.22 \\
\hline \multirow[t]{2}{*}{5} & 0.6 & 0.15 & 0.66 & 1.9 & - & 0.75 & 1.52 & 1.43 & 0.66 & 0.29 & 0.12 & 0.13 \\
\hline & 1.3 & 0.10 & 0.65 & 2.5 & - & 1.40 & 1.27 & 2.42 & 0.79 & 0.23 & 0.15 & 0.11 \\
\hline \multirow[t]{2}{*}{6} & - & 0.10 & 0.92 & 1.9 & 113 & 0.11 & 1.69 & - & 0.59 & $*$ & 0.20 & 0.20 \\
\hline & 0.8 & 0.20 & 0.91 & 3.2 & 0 & 1.10 & 0.50 & 1.88 & 1.99 & 0.25 & 0.24 & 0.18 \\
\hline \multirow[t]{2}{*}{7} & - & 1.40 & 0.90 & 1.7 & 478 & 1.40 & 1.40 & - & 0.71 & $*$ & 1.4 & 4.0 \\
\hline & 1.0 & 0.50 & 0.85 & 2.1 & 310 & 1.50 & 1.42 & 0.32 & 0.70 & 0.51 & 1.1 & 1.6 \\
\hline \multirow[t]{2}{*}{8} & - & 0.30 & 0.45 & 2.5 & 0 & 0.52 & 1.99 & - & 0.50 & $*$ & 1.9 & 4.1 \\
\hline & 0.8 & 0.29 & 0.44 & 2.9 & - & 1.09 & 1.96 & 1.72 & 0.51 & 0.29 & 1.9 & 2.9 \\
\hline \multirow{2}{*}{9} & - & 1.63 & 0.64 & 3.2 & 605 & 1.63 & 2.56 & - & 0.39 & $*$ & 2.7 & 7.0 \\
\hline & 1.2 & 0.81 & 0.64 & 3.1 & - & 2.01 & 1.64 & 2.30 & 0.61 & 0.22 & 2.8 & 3.9 \\
\hline
\end{tabular}

FRC: functional residual capacity; $V$ trap: the volume of gas trapped in the lung above the elastic equilibrium point; $P$ el,st: static elastic recoil pressure; $\left(P \mathrm{el}, \mathrm{st}=\mathrm{k} 0, \mathrm{st}+\mathrm{k} 1, \mathrm{st} \cdot V+\mathrm{k} 2, \mathrm{st} \cdot V^{2}\right.$ where $V$ is volume); $C \mathrm{st}$ : static compliance; $R \mathrm{r}$ : inspiratory resistance; $R \mathrm{E}$ : expiratory resistance; Preinsp.: preinspiratory; Postinsp.: postinspiratory. *: postinspiratory $C_{\text {st }}$ equals preinspiratory $C_{\text {st }}$ in linear models. For further abbreviations see legend to table 1.

When a second degree polynomial was tried, the improvement in the fit was trivial and the sign of the quadratic term was randomly distributed between positive and negative values. Hence, the linear equation was used to describe the $P$ el,st $V$ curve at ZEEP (table 2). At PEEP, however, a nonlinear $P$ el,st $-V$ relationship was evident in most subjects (fig. 4). A second degree polynomial was applied. The quadratic term was found to be positive in all nine cases (both at low and high PEEP in subject No. 5). Accordingly, a second degree polynomial was accepted to describe the $P$ el,st $V$ relationship at PEEP. The positive quadratic term indicates that compliance fell with lung volume.

In ALI/ARDS (subjects 1-6), PEEP caused an increase of FRC to 1.6 times the value at ZEEP (range 1.3-1.8). In COPD (subjects 7-9), the corresponding value was 1.1 (table 2). (The lower value of PEEP in subject No. 5 is regarded as ZEEP in this and the following two paragraphs). The measurement of FRC made it possible to display the $P$ el,st $V$ curves at ZEEP and PEEP on a common volume scale. PEEP caused a displacement of the curve towards higher volumes (fig. 5). This displacement, measured as indicated in figure 5, was on average $0.44 \mathrm{~L}$ (range: $0.12-0.71 \mathrm{~L}$ ) in ALI/ARDS and $0.07 \mathrm{~L}$ in COPD. The compliance at the lowest part of the $P$ el,st $V$ curve, i.e. $\mathrm{k} 1$,st, at PEEP was, in ALI/ARDS, 1.5 times higher than the constant compliance at ZEEP. At the end of inspiration, however, compliance at PEEP was only 0.6 of the value at ZEEP. Compliance in COPD was at PEEP at the start of inspiration similar to the value at ZEEP but fell during insufflation to 0.6 of that value.

The intercept of the static $P$ el,st- $V$ curve corresponded, within $0.1 \mathrm{kPa}$, to measured total PEEP in all instances except in subjects Nos. 3 and 8 at ZEEP. Their measured auto-PEEP was 0.26 and $0.22 \mathrm{kPa}$ lower than the intercept, respectively. Auto-PEEP was in ALI/ARDS at ZEEP on average $0.16 \pm 0.04 \mathrm{kPa}$ and unaffected by PEEP. In COPD auto-PEEP reached $0.3,1.4$ and $1.6 \mathrm{kPa}$ at ZEEP and fell at PEEP in the two latter cases to 0.5 and $0.8 \mathrm{kPa}$ (table 2).

In ALI/ARDS, inspiratory resistance at mid-inflation was 0.38 and $0.30 \mathrm{kPa} \cdot \mathrm{L}^{-1} \cdot \mathrm{s}$ at ZEEP and PEEP, respectively (table 2). The corresponding values of expiratory resistance were 0.36 and $0.23 \mathrm{kPa} \cdot \mathrm{L}^{-1} \cdot \mathrm{s}$. At ZEEP, subjects Nos. 1 and 2 showed higher resistance at endexpiration (fig. 6). Conversely, at PEEP, subjects Nos. 2,5 and 6 disclosed a rise of resistance at maximum inflation. In COPD, mid-inspiratory resistance was 2.0 $\mathrm{kPa} \cdot \mathrm{L}^{-1} \cdot \mathrm{s}$ at ZEEP and $1.9 \mathrm{kPa} \cdot \mathrm{L}^{-1} \cdot \mathrm{s}$ at PEEP. Expiratory resistance at the same volume was $5.0 \mathrm{kPa} \cdot \mathrm{L}^{-1} \cdot \mathrm{s}$ at ZEEP

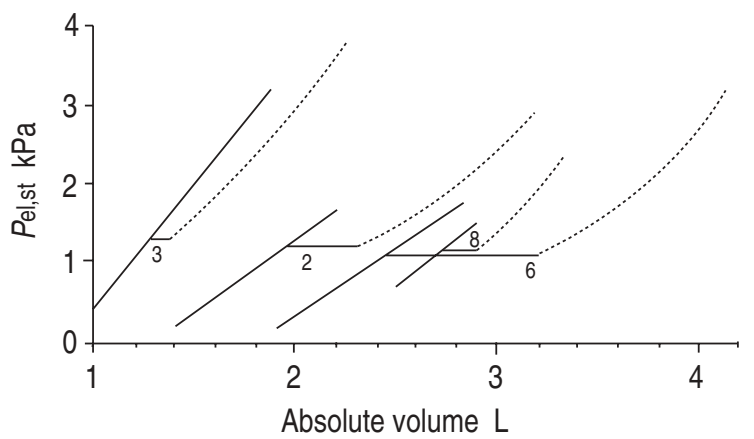

Fig. 5. - The $P$ el,st $/ V$ curves were for subjects Nos. 2, 3, 6 and 8 plotted on an absolute volume scale common for ZEEP (-) and PEEP (-----) according to the calculated polynomials and FRC (table 2). The curves at PEEP were displaced toward higher volumes as indicated by horizontal lines. FRC: functional residual capacity. For further abbreviations see legends to figures 1,3 and 4 . 

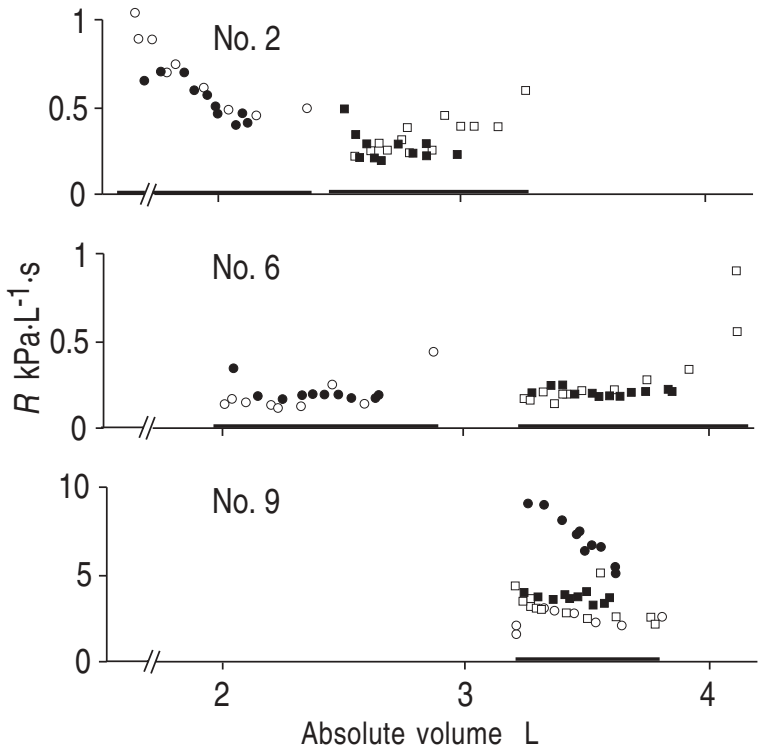

Fig. 6. - Resistance was plotted on an absolute volume scale common to ZEEP and PEEP. The tidal volume is indicated with a thick line along the abscissa. In subject No. 9 the tidal volume covered similar absolute volume range at ZEEP and PEEP. $\bigcirc$ : ZEEP inspiration; • : ZEEP expiration; $\square$ : PEEP inspiration; $\mathbf{\square}$ : PEEP expiration. For abbreviations see legends to figures 1,3 and 4 .

Table 3. - Non-Newtonian properties: linear model

\begin{tabular}{lccccc}
\hline $\begin{array}{l}\text { Sub } \\
\text { No. }\end{array}$ & $\begin{array}{c}\text { PEEP } \\
\mathrm{kPa}\end{array}$ & $\begin{array}{c}\tau_{\mathrm{ve}} \\
\mathrm{s}\end{array}$ & $\begin{array}{c}C_{\mathrm{ve}} \\
\mathrm{L} \cdot \mathrm{kPa}^{-1}\end{array}$ & $\begin{array}{c}R \mathrm{ve} \\
\mathrm{kPa} \cdot \mathrm{L}^{-1} \cdot \mathrm{s}\end{array}$ & $\begin{array}{c}\mathrm{MSD} \\
\mathrm{kPa}^{2}\end{array}$ \\
\hline ALI & & & & & \\
1 & 0 & 0.63 & 2.4 & 0.26 & 0.0001 \\
1 & 1.0 & 0.52 & 2.2 & 0.24 & 0.0009 \\
2 & 0 & 0.67 & 1.5 & 0.44 & 0.0009 \\
3 & 0 & 0.67 & 0.9 & 0.73 & 0.0044 \\
4 & 0 & 0.42 & 1.1 & 0.37 & 0.0001 \\
6 & 0 & 0.65 & 1.7 & 0.37 & 0.0012 \\
COPD & & & & & \\
8 & 0 & 0.49 & 1.0 & 0.48 & 0.0015 \\
\hline
\end{tabular}

$\tau_{\mathrm{ve}}$ : viscoelastic time constant; Cve: viscoelastic compliance; $R$ ve: viscoelastic resistance; MSD: mean squared deviation between observed data points and the calculated curve of the pressure over the viscoelastic unit-volume $\left(P_{\mathrm{ve}}-V\right)$ loop. For further abbreviations see legend to table 1 . and increased further to much higher values during late expiration (fig. 6). At PEEP, inspiratory and expiratory resistance did not significantly vary with lung volume in COPD.

\section{Non-Newtonian behaviour}

The linear model gave a proper fit between observed and calculated values of $P_{\text {ve }}$ in five subjects studied at ZEEP (subjects Nos. 1-4 and 8) (fig. 4). According to the F-test, no significant improvement of the fit could be obtained with a nonlinear model. The linear model was then accepted. In these cases, average $C$ ve was 1.4 $\mathrm{L} \cdot \mathrm{kPa}^{-1}, R$ ve $0.46 \mathrm{kPa} \cdot \mathrm{L}^{-1} \cdot \mathrm{s}$ and $\tau_{\mathrm{ve}} 0.58 \mathrm{~s}$ (table 3 ). The mean squared deviation between observed data points and the calculated $P$ ve- $V$ loop was $0.0014 \mathrm{kPa}^{2}$.

In the remaining recordings in ALI/ARDS patients, i.e. one at ZEEP and all seven at PEEP, the mean squared deviation between observed $P_{\text {ve }}$ data points and the trajectory based on the linear model was larger, on average $0.0039 \mathrm{kPa}^{2}$. Furthermore, the shape of the calculated trajectory differed systematically from the experimental data points (fig. 4). By allowing the value of $C_{\mathrm{ve}}$ to be volume-dependent, the mean squared difference fell to on average $0.0010 \mathrm{kPa}^{2}$. The systematic deviation in shape between observed data points and the calculated trajectory disappeared. According to the F-test, the higher order model, based on a volume-dependent capacitor, offered a significant improvement $(\mathrm{p}<0.01)$. Accordingly, the model based on a volume dependent capacitor was accepted with the results given in table 4 .

In the remaining five records, which were obtained in COPD patients, the linear model resulted in large and systematic deviation between data points and calculated trajectory. The nonlinear model did not improve the fit in any of these records. When the composite model was applied, the mean squared difference fell to on average $0.0007 \mathrm{kPa}^{2}$. The systematic difference between data points and trajectory disappeared (fig. 4) $(\mathrm{p}<0.01)$. The coefficients of the composite non-Newtonian model are given in table 4.

Table 4. - Non-Newtonian properties: nonlinear model and composite model

\begin{tabular}{|c|c|c|c|c|c|c|c|c|c|}
\hline \multirow{3}{*}{$\begin{array}{l}\text { Sub } \\
\text { No. }\end{array}$} & \multirow{3}{*}{$\begin{array}{l}\text { PEEP } \\
\mathrm{kPa}\end{array}$} & \multicolumn{2}{|c|}{$P_{\mathrm{ve}}$} & \multicolumn{2}{|c|}{$C_{\mathrm{ve}}$} & \multirow{3}{*}{$\begin{array}{c}R_{\mathrm{ve}} \\
\mathrm{kPa} \cdot \mathrm{L}^{-1} \cdot \mathrm{s}\end{array}$} & \multirow{3}{*}{$\begin{array}{c}C_{\mathrm{ve}, \mathrm{E}} \\
\mathrm{L} \cdot \mathrm{kPa}^{-1}\end{array}$} & \multirow{3}{*}{$\begin{array}{c}R \mathrm{ve}, \mathrm{E} \\
\mathrm{kPa} \cdot \mathrm{L}^{-1} \cdot \mathrm{s}\end{array}$} & \multirow{3}{*}{$\begin{array}{l}\mathrm{MSD} \\
\mathrm{kPa}^{2}\end{array}$} \\
\hline & & $\mathrm{k} 1$,ve & $\mathrm{k} 2$,ve & Preinsp. & Postinsp. & & & & \\
\hline & & $\mathrm{kPa} \cdot \mathrm{L}^{-1}$ & $\mathrm{kPa} \cdot \mathrm{L}^{-2}$ & $\mathrm{~L} \cdot \mathrm{kPa}^{-1}$ & $\mathrm{~L} \cdot \mathrm{kPa}^{-1}$ & & & & \\
\hline \multicolumn{10}{|l|}{ ARF } \\
\hline 2 & 1.2 & 0.29 & 0.56 & 3.4 & 0.86 & 0.71 & - & - & 0.0007 \\
\hline 3 & 1.0 & 0.88 & 0.77 & 1.1 & 0.44 & 1.05 & - & - & 0.0033 \\
\hline 4 & 1.0 & 0.56 & 0.98 & 1.8 & 0.51 & 0.50 & - & - & 0.0004 \\
\hline 5 & 0.6 & 0.35 & 0.65 & 2.8 & 0.83 & 0.65 & - & - & 0.0005 \\
\hline 5 & 1.3 & 0.77 & 1.56 & 1.3 & 0.36 & 0.95 & - & - & 0.0012 \\
\hline 6 & 0.8 & 0.72 & 1.13 & 1.4 & 0.36 & 0.87 & - & - & 0.0009 \\
\hline \multicolumn{10}{|l|}{ COPD } \\
\hline 7 & 0 & $0.12 *$ & $0.54 *$ & $8.2 *$ & $0.92 *$ & $0.45^{*}$ & 1.11 & 0.62 & 0.0007 \\
\hline 7 & 1.0 & $0.66^{*}$ & $0.79 *$ & $1.5^{*}$ & $0.50 *$ & $0.52 *$ & 0.98 & 0.62 & 0.0003 \\
\hline 8 & 0.8 & $0.39 *$ & $2.28 *$ & $2.6^{*}$ & $0.42 *$ & $1.17 *$ & 0.44 & 1.17 & 0.0006 \\
\hline 9 & 0 & $0.68^{*}$ & $1.09 *$ & $1.5^{*}$ & $0.48^{*}$ & $1.18^{*}$ & 0.41 & 0.95 & 0.0009 \\
\hline 9 & 1.2 & $0.81^{*}$ & $1.42 *$ & $1.2 *$ & $0.38^{*}$ & $1.22 *$ & 0.49 & 1.07 & 0.0010 \\
\hline
\end{tabular}

$P_{\mathrm{ve}}=\mathrm{k} 1$,ve $\cdot V_{\mathrm{ve}}+\mathrm{k} 2$, ve $\cdot V_{\mathrm{ve}}^{2}$ where $V_{\mathrm{ve}}$ is volume charge over capacitator $\left(C_{\mathrm{ve}}\right) ; C_{\mathrm{ve}, \mathrm{E}}$ : expiratory compliance; $R_{\mathrm{ve}, \mathrm{E}}$ : expiratory resistance; MSD: mean squared deviation between observed data points and the calculated trajectory. *: the composite model. Data are valid for inspiration only. For further abbreviations see legends to tables 1-3. 


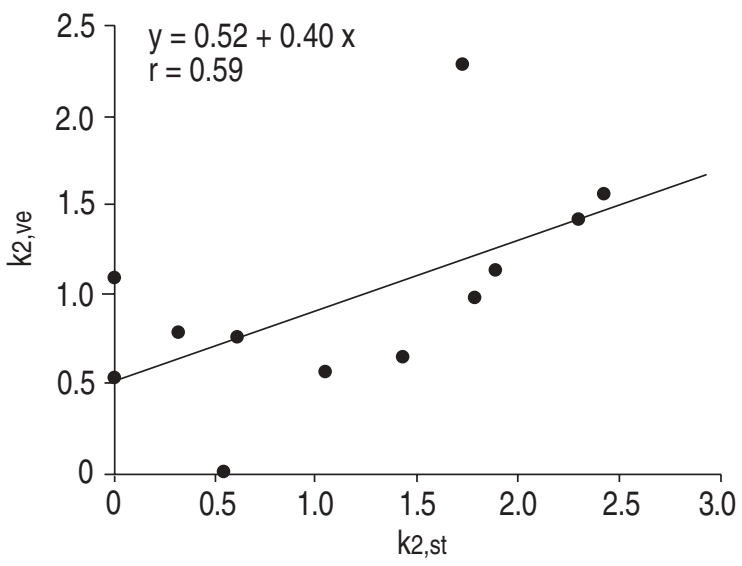

Fig. 7. - Regression between coefficients relating to nonlinearity of $C_{\mathrm{st}}$ and $C_{\mathrm{ve}}, \mathrm{k} 2$,st and k2,ve, respectively (tables 2 and 4). For abbreviations see legend to figure 1 .

Table 5. - Pressure and work of the viscoelastic unit and total work

\begin{tabular}{|c|c|c|c|c|c|c|c|}
\hline \multirow[b]{2}{*}{$\begin{array}{l}\text { Sub } \\
\text { No. }\end{array}$} & \multirow[b]{2}{*}{$\begin{array}{c}\text { PEEP } \\
\mathrm{kPa}\end{array}$} & \multirow[b]{2}{*}{$\begin{array}{l}V \mathrm{~T} \\
\mathrm{~L}\end{array}$} & \multicolumn{2}{|c|}{$P_{\mathrm{ve}}$} & \multirow[b]{2}{*}{$\begin{array}{c}W_{\mathrm{ve}} \\
\mathrm{kPa} \cdot \mathrm{L}\end{array}$} & \multirow[b]{2}{*}{$\begin{array}{l}W \text { tot } \\
\mathrm{kPa} \cdot \mathrm{L}\end{array}$} & \multirow[b]{2}{*}{$\begin{array}{c}W_{\mathrm{ve}} / \mathrm{W}_{\text {tot }} \\
\%\end{array}$} \\
\hline & & & $\begin{array}{l}\max \\
\mathrm{kPa}\end{array}$ & $\begin{array}{l}\min \\
\mathrm{kPa}\end{array}$ & & & \\
\hline \multirow[t]{2}{*}{1} & - & 0.68 & 0.14 & -0.06 & 0.07 & 0.32 & 22 \\
\hline & 1.0 & 0.68 & 0.17 & -0.07 & 0.08 & 0.27 & 30 \\
\hline \multirow[t]{2}{*}{2} & - & 0.79 & 0.26 & -0.13 & 0.14 & 0.76 & 19 \\
\hline & 1.2 & 0.78 & 0.39 & -0.04 & 0.14 & 0.51 & 29 \\
\hline \multirow[t]{2}{*}{3} & - & 0.88 & 0.56 & -0.32 & 0.44 & 1.05 & 42 \\
\hline & 1.0 & 0.92 & 0.74 & -0.23 & 0.43 & 0.99 & 44 \\
\hline \multirow[t]{2}{*}{4} & - & 0.59 & 0.23 & -0.13 & 0.12 & 0.39 & 30 \\
\hline & 1.0 & 0.71 & 0.34 & -0.08 & 0.14 & 0.42 & 33 \\
\hline \multirow[t]{2}{*}{5} & 0.6 & 0.66 & 0.26 & -0.05 & 0.06 & 0.20 & 29 \\
\hline & 1.3 & 0.65 & 0.48 & -0.09 & 0.13 & 0.29 & 45 \\
\hline \multirow[t]{2}{*}{6} & - & 0.92 & 0.33 & -0.09 & 0.18 & 0.44 & 42 \\
\hline & 0.8 & 0.91 & 0.57 & -0.12 & 0.28 & 0.67 & 41 \\
\hline \multirow[t]{2}{*}{7} & - & 0.90 & 0.28 & -0.20 & 0.22 & 2.07 & 11 \\
\hline & 1.0 & 0.85 & 0.37 & -0.20 & 0.24 & 1.25 & 19 \\
\hline \multirow[t]{2}{*}{8} & - & 0.45 & 0.18 & -0.07 & 0.06 & 0.76 & 9 \\
\hline & 0.8 & 0.44 & 0.29 & -0.18 & 0.10 & 0.67 & 16 \\
\hline \multirow[t]{2}{*}{9} & - & 0.64 & 0.42 & -0.26 & 0.20 & 2.64 & 8 \\
\hline & 1.2 & 0.64 & 0.50 & -0.23 & 0.23 & 2.39 & 9 \\
\hline
\end{tabular}

Wve: work of breathing of the viscoelastic unit; $W$ tot: total work of breathing; max: maximum; min: minimum. For further abbreviations see legends to tables 1 and 3 .
There was a significant correlation between the coefficients relating to nonlinearity of $C_{\mathrm{st}}$ and $C$ ve, i.e. k2,st and $\mathrm{k} 2$,ve $(\mathrm{p}<0.05)$ (fig. 7).

$P$ ve reached, on average, a maximum of $0.36 \mathrm{kPa}$ during inspiration and a minimum of $-0.14 \mathrm{kPa}$ during expiration (table 5). At the end of expiration, $P$ ve was consistently negative and, on average, $-0.1 \mathrm{kPa}$. The work dissipated in the viscoelastic unit averaged $0.18 \mathrm{kPa} \cdot \mathrm{L}(\mathrm{J})$. In ALI/ARDS the non-Newtonian work amounted to an average of $34 \%$ of the total work dissipated in the respiratory system (range 19-45\%), and only $12 \%$ in COPD. The energetics of the respiratory system may be illustrated efficiently by a composite diagram depicting $P$ tot, $P$ el,dyn, and $P$ el,st during the full respiratory cycle (fig. 8).

\section{Discussion}

\section{Methods}

The method applied in this study extends the information of mechanics to the complete breathing cycle [17]. The determination of FRC [25], at the prevailing pattern of ventilation, allows deeper analysis, e.g. of the effect of PEEP. The ventilation of the patient is undisturbed during all measurements, apart from interruptions during study breaths. The numerical technique allowed us to test the validity of the classical model for nonNewtonian behaviour during inspiration as well as during expiration, and to test modifications of that model with nonconstant values of $R$ ve and $C$ ve. It is noteworthy that the analysis of such more composite models was based on simple mathematics, Equation (2).

We used a device for external control of the ventilator frequency that was only active during the particular phase of a study breath to be analysed. Thereby, we maintained the volume history preceding all study breaths to be unaffected. This may be particularly important in studies of patients in whom the situation is not static before inspiration, i.e. in patients in whom flow continues until the end of expiration because of auto-PEEP.

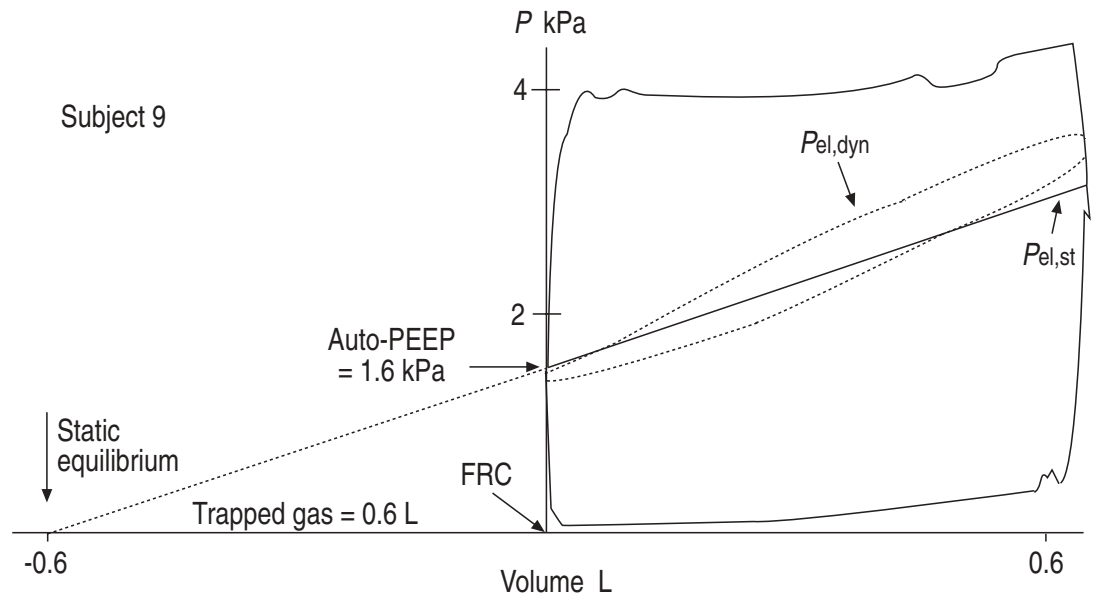

Fig. 8. - Mechanical behaviour of the respiratory system can be comprehensively illustrated by a composite pressure-volume $(P-V)$ diagram, subject No. 9. The total tracheal pressure (outer loop) comprises $P_{\text {res }}, P$ el,st and $P_{\text {ve. }}\left(P\right.$ el,st $\left.+P_{\text {ve }}\right)$ represents dynamic elastic recoil $(P$ el,dyn $)$ (inner loop). This loop is cut by the $P$ el,st curve. In this example, the $P$ el,st $-V$ curve when extrapolated hit the static equilibrium point of the volume axis, which was reached after expiration of $0.6 \mathrm{~L}$ of trapped gas. This was not observed in each case. FRC was $3.17 \mathrm{~L}$. For abbreviations see legends to figures 1 and 5. 
A description of the device is available from the authors. Heart artefacts in tracheal pressure were five times larger than in normal subjects [17], and of similar size, as shown by D'ANGELo and co-workers [5, 6]. We regard heart artefact attenuation as an important measure for accurate measurements. Likewise, direct measurement of tracheal pressure is favourable to avoid errors associated with subtraction of pressure across the tracheal tube [26].

Continuing gas exchange during a pause of lung ventilation may lead to artefacts in determination of $P$ el,st and $P_{\mathrm{ve}}$, since the respiratory quotient (RQ) differs from zero. A value of RQ lower than 1.0 implies that the lung loses volume and that $P$ el,st falls. During a prolonged pause, RQ may fall to low values, as has been discussed by ShardONOFSKy et al. [27]. Pel,st will be underestimated, whilst $P$ ve will be attributed a numerical value that is too high. If oxygen consumption in a relaxed subject is $200 \mathrm{~mL} \cdot \mathrm{min}^{-1}$ and RQ during the first $2 \mathrm{~s}$ after flow interruption is assumed to be in the range 0.85-0.5, the error will be $0.004-0.012 \mathrm{kPa}$ at a static compliance of $0.25 \mathrm{~L} \cdot \mathrm{kPa}^{-1}$. Errors of this magnitude would affect all values of $P$ el,st and $P_{\mathrm{ve}}$, which means that the whole $P-V$ curve would be slightly displaced. In nonlinear systems, the displacement of individual points of observation may vary within these limits.

$P$ el,st was read $2 \mathrm{~s}$ after flow interruption. This interval is shorter than in most other studies $[5-7,10]$. The pause should be long enough to allow $P_{\text {ve }}$ to decay to insignificant values but not so long that continuing absorption of oxygen leads to a volume change. If the pause was too short, $P$ el,st during inspiration would have been overestimated, whilst during expiration it would have been underestimated. This would have led to an artefactual hysteresis of $P \mathrm{el}, \mathrm{st}-V$ that we did not find. It is, nevertheless, unquestionable that the short pause after which $P$ el,st was read means that $P_{\text {ve }}$ has not completely decayed. The error of $P$ el,st thereby introduced leads to errors of determinations of $P$ ve as has been mentioned. As the latter error is within $10 \%$ according to theoretical estimates the pause is still two or three times longer than $\tau_{\mathrm{ve}}$ that would allow $90-95 \%$ of $P_{\mathrm{ve}}$ to decay during the pause (Equation (6)). As gas exchange motivates shortest possible pause after which $P$ el,st is read a pause of $2 \mathrm{~s}$ is rationally motivated.

Resistance was determined from the pressure change occurring at interruption of flow rate. Flow interruption was performed with the Servo Ventilator 900C valves, as in several other studies $[8,11]$. To compensate for the volume change occurring during the interruption, this volume change was measured. This was possible with the flow measurement system that has an adequate frequency response to record events during valve closure. This technique, which has been described previously [17], represents a development of previous techniques for correction of finite closing time of the valve [23, 28]. Nevertheless, particularly in the presence of serial pendelluft in obstructive disease, resistance determined in conjunction with flow interruption may be frequencydependent [1] and, therefore, to some extent related to dynamic properties of valves and recording technique.
This can hardly invalidate variations in resistance observed in specific cases.

The behaviour of the linear model at constant inspiratory flow can be described with solvable equations $[5-8,10]$. Non-Newtonian behaviour has been expressed in terms of concepts such as "additional resistance", $\Delta R$ rs. $\Delta R_{\mathrm{rs}}$ is defined as the quotient $P_{\mathrm{ve}} / V^{\prime}$ and is supposed to increase from zero during insufflation [5, 8]. This is not the case in healthy [17] or, as we have shown, in diseased subjects. $P_{\mathrm{ve}} / V^{\prime}$ is negative during early expiration and inspiration. This implies that $P_{\text {ve }}$ contributes to drive flow and that $\Delta R$ rs would be negative. We therefore avoided expressing our data in terms of $\Delta R$ rs.

\section{Patients}

We have focused on those patient groups which are associated with the greatest problems related to ventilation. This is in agreement with many other studies [4, $12-14,18,29]$. The number of patients is small. However, the results show a notable consistency from many aspects, such as absence of static hysteresis, nonlinearity of non-Newtonian behaviour at PEEP, and nonvalidity of the traditional lung model when PEEP is applied in ALI/ARDS. This suggests that the results are valid in important groups of patients. Further studies in complementary groups are needed, such as patients in the most acute stage of critical disease.

\section{Static elastic recoil}

In conformity with reports concerning humans and dogs $[17,27,30]$, no significant hysteresis of $P$ el,st over volume was found. An important hysteresis has previously been observed with the super syringe technique in acute respiratory failure [21]. It has later been shown that this technique gives rise to a hysteresis mainly due to continuing gas exchange $[30,31]$. Our technique eliminates this problem. In addition, with our technique there is no pause before the study breaths during which closure of lung compartments might consolidate. Considering differences in recording technology, our results are not in conflict with previous reports. The absence of hysteresis suggests that surfactant hysteresis is unimportant for stability of the lung under tidal breathing in disease as has been shown in health [17]. Absence of hysteresis implies either that significant closing and reopening of airways during tidal breathing does not occur, or that opening of lung units during inspiration occurs at the same volume as that at which they close during expiration. The latter mechanism may be possible as reopening forces caused by interdependence between lung units are very important [32].

At ZEEP we observed a linear $P$ el,st $V$ relationship. The curve did not pass the origin. In ALI/ARDS the intercept with the $P$ el,st axis equalled $0.24 \mathrm{kPa}$. The deviation from zero can represent auto-PEEP [33]. The value of the intercept was much smaller than "best PEEP" determined with the super syringe technique. This might be 
explained by the different volume history preceding the two sets of data. Before inflation with the super syringe, the lung is allowed to return to the elastic equilibrium volume at which airways have ample time to close and alveoli to collapse. The insufflation will then initially lead to reopening of closed units leading to the inflection point described by Matamis et al. [22]. Before our $P$ el,st $-V$ data were recorded, the lung did not completely return to the elastic equilibrium volume. This implies that our volume reference corresponds to a volume greater than zero for the super syringe technique. Furthermore, no pause existed before the study breaths. The finding of a linear $P$ el,st $V$ curve from the first recorded static $P-V$ point may be evidence that due to these factors breathby-breath airway closure and recruitment was minimal even at ventilation with ZEEP.

In ALI/ARDS, PEEP caused a recruitment of lung units as indicated by the shift of the $P$ el,st $V$ curves to higher lung volumes and by higher preinspiratory compliance values compared to ZEEP (table 2). At PEEP, the nonlinearity of the $P$ el,st $V$ curve was so important that postinspiratory compliance was much lower than compliance at ZEEP (table 2). When PEEP was set according to the super syringe measurement [21] and ordinary tidal volumes were used, a notable nonlinearity of the $P$ el,st $-V$ curve was observed. Similar observations have been regarded as evidence of lung overdistension [34]. In COPD, PEEP caused neither a significant displacement of the $P$ el,st $-V$ curve nor an increase of compliance. Accordingly, PEEP did not cause significant recruitment in COPD. This is in agreement with common findings of overdistension and auto-PEEP in COPD [24].

\section{Newtonian resistance}

In ALI/ARDS, resistance at ZEEP was about twice as high as in health [17]. This accords with previous observations $[9,14]$. The particularly high resistance that we observed at very low lung volumes during inspiration and expiration probably reflects closure or narrowing of small airways [9]. Lower resistance at PEEP may be another effect of recruitment. The increase of resistance toward the end of inspiration at PEEP supports the hypothesis of overdistension related to longitudinal stretching of airways, as suggested by EISSA et al. [9].

In COPD, PEEP did not affect inspiratory resistance but dramatically reduced expiratory resistance. $P$ el,dyn that was not increased by PEEP drives expiratory flow from alveoli to atmosphere. At PEEP, the braking effect of the expiratory valve moderates the expiratory flow rate and, thereby, attenuates dynamic compression of intrathoracic airways. This explains the lower expiratory resistances observed under PEEP.

\section{Non-Newtonian behaviour}

In ALI/ARDS and at ZEEP, the linear model usually adequately explained non-Newtonian behaviour of the respiratory system during the complete breathing cycle, as in healthy subjects [17]. $\tau_{\mathrm{ve}}$ was lower than in normal subjects because of lower values of $C$ ve, whilst $R$ ve was in the normal range. $P$ ve and non-Newtonian work reached higher values than in normal subjects. This reflects lower $C$ ve, but also larger tidal volumes. In ALI/ARDS at PEEP, the linear model of the viscoelastic unit was shown to be invalid.

In the choice between alternative models, we were guided by the fact that values of $P_{\mathrm{ve}}$ observed during inspiration deviated more and more in the positive direction compared to a course calculated according to the traditional model. The data observed even showed an upward concavity during a part of inspiration. We considered that this might be due to multiple linear viscoelastic units connected in series. However, the observations cannot be explained by such a model as each of such compartments must obey Equation (1), which at constant inspiratory flow implies that the rate of increase of $P_{\mathrm{ve}}$ will always decrease with time and with volume. If a nonconstant $R$ ve should explain the observation during inspiration, it appears from Equation (2) that $R$ ve only affects its second term that can be regarded as a description of spontaneous relaxation within the viscoelastic unit [17]. A constant or accelerating build-up of $P_{\text {ve }}$ during inspiration at constant flow could, in theory, be due to an increasing $R$ ve that would limit this rate of relaxation. However, a hypothesis that Rve should behave in such a way cannot be founded on any other observation. In contrast, the static elastic properties of the respiratory system showed a nonlinearity in the cases with a poor fit between observed and theoretical $P_{\text {ve }}$ values. This observation was the basis for the hypothesis that in the presence of nonlinear static elastic elements the capacitor of the viscoelastic unit might be nonlinear. The introduction of a nonlinear capacitor $\left(C_{\mathrm{ve}}\right)$ was found to provide a good fit between observations and model behaviour in ALI/ARDS. The validity of such a nonlinear capacitor in ALI/ARDS at PEEP can obviously not be proved. However, the model represented by a nonconstant capacitor gave a significantly better fit as compared to that obtained with the linear model. The significance of the observation is enhanced by the fact that the sign of the quadratic term $\mathrm{k} 2$,ve was always positive rather than randomly distributed. The observation that $\mathrm{k} 2$,ve showed a significant correlation to $\mathrm{k} 2$,st gives support to the hypothesis that these two factors are linked to the elastic properties of the tissues of the respiratory system that are overdistended at PEEP. Considering that the value of the capacitor, $C$ ve, fell during inflation to $29 \%$ of its preinspiratory value, nonlinearity is prominent. The swing of $P$ ve during the respiratory cycle was, in each subject, higher at PEEP than at ZEEP and in one patient (subject No. 3) reached $0.97 \mathrm{kPa}$. Hence, the viscoelastic unit is much involved in the energetics of the respiratory system in ALI/ARDS and particularly at PEEP.

Non-Newtonian behaviour is usually considered to reflect stress relaxation of tissue and pendelluft. In addition, shifts of intrathoracic blood pools during the respiratory cycle may contribute. A study of the present kind cannot prove the basic nature of non-Newtonian 
phenomena. However, as concerns the nonlinearity of the capacitor, $C$ ve, this was statistically correlated to the nonlinearity of $C$ st. The nonlinearity was only prominent when the lung volume was increased by PEEP, at which ventilation inhomogeneity is expected to be less than at lower volumes. These findings provide circumstantial evidence that the nonlinearity of $C_{\text {ve reflects tis- }}$ sue stress relaxation rather than pendelluft.

In COPD, non-Newtonian behaviour did not accord with either the linear or the nonlinear model. As pendelluft may contribute to non-Newtonian behaviour, particularly in COPD, we hypothesized that high expiratory airway resistance might lead to high expiratory $R$ ve. With different inspiratory and expiratory values of $C_{\mathrm{ve}}$ and $R$ ve, the model did concur with the data observed. However, $C$ ve rather than $R$ ve differed between expiration and inspiration. This unexpected finding weakens the foundation of the "composite model". Information from other types of experiments is needed to establish a basis on which modelling of non-Newtonian behaviour of COPD can progress. Nevertheless, the composite model allows adequate simulation of the course $P_{\mathrm{ve}}$ during a breath and is useful for calculation of non-Newtonian work of breathing.

\section{Work of breathing}

Non-Newtonian work per breath was about three times as high in ALI/ARDS and COPD as in normal subjects [17]. In ALI/ARDS at PEEP, it constituted a high fraction of total work of breathing. In COPD, the important work against airway resistance reduces the relative weight of non-Newtonian work to about $10 \%$ of total work. A postinspiratory pause of $0.4 \mathrm{~s}$ at a $\tau_{\mathrm{ve}}$ of $0.5 \mathrm{~s}$ will lead to a decay of $P$ ve of about $50 \%$, Equation (6). This release of elastic recoil represents a loss of energy, which without a pause would have served to promote expiratory flow. It will also lessen the elastic widening forces on intrathoracic airways during expiration. Furthermore, the pause implies that less time is available for ventilation. It is not known whether these negative effects of a pause are balanced by improved gas exchange.

\section{Conclusion}

In conclusion, in a spectrum of patients with critical lung disease, static elastic hysteresis of the respiratory system is insignificant and does not contribute to stable lung inflation. PEEP causes an important recruitment of lung units in ALI/ARDS but not in COPD. When "best PEEP" in ALI/ARDS was combined with ordinary tidal volumes, we observed signs commonly thought to indicate overdistension. The classical model of nonNewtonian behaviour usually applies in ALI/ARDS at ZEEP but not at PEEP, when the elastic elements are overdistended. Then, a nonlinear elastic element of the viscoelastic unit must be taken into consideration. In COPD, PEEP reduces expiratory resistance by decreasing dynamic compression. Non-Newtonian behaviour is composite in COPD. A model with different properties during inspiration and expiration mimics non-Newtonian behaviour in COPD but needs further exploration.

\section{References}

1. Bates JHT, Baconnier P, Milic-Emili J. A theoretical analysis of interrupter technique for measuring respiratory mechanics. J Appl Physiol 1988; 64: 2204-2214.

2. Bates JHT, Rossi A, Milic-Emili J. Analysis of the behavior of the respiratory system with constant inspiratory flow. J Appl Physiol 1985; 58: 1840-1848.

3. Auler JOC, Saldiva PHN, Martins MA, et al. Flow and volume dependence of respiratory system mechanics during constant flow ventilation in normal subjects and in adult respiratory distress syndrome. Crit Care Med 1990; 18: 1080-1086.

4. Broseghini C, Brandolese R, Poggi R, et al. Respiratory mechanics during the first day of mechanical ventilation in patients with pulmonary edema and chronic airway obstruction. Am Rev Respir Dis 1988; 138: 355361 .

5. D'Angelo E, Calderini E, Torri G, Robatto FM, Bono D, Milic-Emili J. Respiratory mechanics in anesthetized paralyzed humans: effects of flow, volume, and time. J Appl Physiol 1989; 67: 2556-2564.

6. D'Angelo E, Robatto FM, Calderini E, et al. Pulmonary and chest wall mechanics in anesthetized paralyzed humans. J Appl Physiol 1991; 70: 2602-2610.

7. D'Angelo E, Calderini E, Tavola M, Bono D, Milic-Emili J. Effect of PEEP on respiratory mechanics in anesthetized paralyzed humans. J Appl Physiol 1992; 73 : 1736-1742.

8. Eissa NT, Ranieri VM, Corbeil C, et al. Analysis of behavior of the respiratory system in ARDS patients: effects of flow, volume and time. J Appl Physiol 1991; 70: 2719-2729.

9. Eissa NT, Ranieri VM, Corbeil C, Chassé M, Braidy J, Milic-Emili J. Effects of positive end-expiratory pressure, lung volume, and inspiratory flow on interrupter resistance in patients with adult respiratory distress syndrome. Am Rev Respir Dis 1991; 144: 538-543.

10. Eissa NT, Ranieri VM, Corbeil C, Chassé M, Braidy J, Milic-Emili J. Effect of PEEP on the mechanics of the respiratory system in ARDS patients. J Appl Physiol 1992; 73: 1728-1735.

11. Pesenti A, Pelosi P, Rossi N, Virtuani A, Brazzi L, Rossi A. The effects of positive end-expiratory pressure on respiratory resistance in patients with the adult respiratory distress syndrome and in normal anesthetized subjects. Am Rev Respir Dis 1991; 144: 101-107.

12. Polese G, Rossi A, Appendini L, Brandi G, Bates JHT, Brandolese R. Partitioning of respiratory mechanics in mechanically ventilated patients. J Appl Physiol 1991; 71: 2425-2433.

13. Prezant DJ, Aldrich TK, Karpel JP, Park SS. Inspiratory flow dynamics during mechanical ventilation in patients with respiratory failure. Am Rev Respir Dis 1990; 142: 1284-1287.

14. Rossi A, Gottfried SB, Higgs BD, Zocchi L, Grassino A, Milic-Emili J. Respiratory mechanics in mechanically-ventilated patients with respiratory failure. $J \mathrm{Appl}$ Physiol 1985; 58: 1849-1858.

15. Tantucci C, Corbeil C, Chassé M, Braidy J, Matar N, 
Milic-Emili J. Flow resistance in patients with chronic obstructive pulmonary disease in acute respiratory failure. Am Rev Respir Dis 1991; 144: 384-389.

16. Tantucci $\mathrm{C}$, Corbeil $\mathrm{C}$, Chassé $\mathrm{M}$, et al. Flow and volume dependence of respiratory system flow resistance in patients with adult respiratory distress syndrome. Am Rev Respir Dis 1992; 145: 355-360.

17. Jonson B, Beydon L, Brauer K, Månsson C, Valind S, Grytzell H. Mechanics of respiratory system in healthy anesthetized humans with emphasis on viscoelastic properties. J Appl Physiol 1993; 75: 132-140.

18. Gottfried SB, Rossi A, Higgs BD, et al. Noninvasive determination of respiratory system mechanics during mechanical ventilation for acute respiratory failure. Am Rev Respir Dis 1985; 131: 414-420.

19. Jansson L, Jonson B. A theoretical study on flow patterns of ventilators. Scand J Respir Dis 1972; 53: 237-246.

20. Bernard GR, Artigas A, Brigham KL, and the Consensus Committe. The American-European Consensus Conference on ARDS. Definitions, mechanisms, relevant outcomes, and clinical trial coordination. Am J Respir Crit Care Med 1994; 149: 818-824.

21. Gattinoni L, Pesenti A, Avalli L, Rossi F, Bombino M. Pressure-volume curve of total respiratory system in acute respiratory failure. Am Rev Respir Dis 1987; 136: 730 736.

22. Matamis D, Lemaire F, Harf A, Brun-Buisson C, Ansquer JC, Atlan G. Total respiratory pressure-volume curves in the adult respiratory distress syndrome. Chest 1984; 86: 58-66.

23. Kochi T, Okubo S, Zin WA, Milic-Emili J. Flow and volume dependence of pulmonary mechanics in anesthetized cats. J Appl Physiol 1988; 64: 441-450.

24. Jonson B, Nordström L, Olsson SG, Akerback D. Monitoring of ventilation and lung mechanics during automatic ventilation: a new device. Bull Eur Physiopathol Respir 1975; 11: 729-743.
25. Larsson A, Linnarsson D, Jonmarker C, Jonson B, Larsson $\mathrm{H}$, Werner $\mathrm{O}$. Measurement of lung volume by sulfur hexafluoride wash-out during spontaneous and controlled ventilation: further development of a method. Anesthesiology 1987; 67: 543-550.

26. Wright PE, Marini JJ, Bernard GR. In vitro versus in vivo comparison of endotracheal tube airflow resistance. Am Rev Respir Dis 1989; 140: 10-16.

27. Shardonofsky FR, Sato J, Bates JHT. Quasi-static pressure-volume hysteresis in the canine respiratory system in vivo. J Appl Physiol 1990; 68: 2230-2236.

28. Bates JHT, Hunter IW, Sly PD, Okubo S, Filiatrault S, Milic-Emili J. Effects of valve closure time on the determination of respiratory resistance by flow interruption. Med Biol Eng Comput 1987; 25: 136-140.

29. Bernasconi M, Ploysongsang Y, Gottfried SB, MilicEmili J, Rossi A. Respiratory compliance and resistance in mechanically ventilated patients with acute respiratory failure. Intensive Care Med 1988; 14: 547-553.

30. Sydow M, Burchardi H, Zinserling J, Ische H, Crozier ThA, Weyland W. Improved determination of static compliance by automated single volume steps in ventilated patients. Intensive Care Med 1991; 17: 108-114.

31. Dall'ava-Santucci J, Armaganidis A, Brunet F, et al. Causes of error of respiratory pressure-volume curves in paralyzed subjects. J Appl Physiol 1988; 64: 42-49.

32. Mead J, Takishima T, Leith D. Stress distribution in lungs: a model of pulmonary elasticity. J Appl Physiol 1970; 28: 596-608.

33. Levy P, Similowski T, Corbeil C, et al. A method for studying the static volume-pressure curves of the respiratory system during mechanical ventilation. J Crit Care 1989; 4: 83-89.

34. Roupie E, Dambrosio M, Servillo G, et al. Titration of tidal volume and induced hypercapnia in the acute respiratory distress syndrome. Am J Respir Crit Care Med 1995; 152: 121-128. 